\title{
Outcome of Excision with Primary Midline Closure for Sacrococcygeal Pilonidal Sinus Disease
}

\author{
Bahzad Waso Hamad \\ Directorate of Research Center \\ University of Raparin \\ Rania,sulaimani,Iraq \\ Bahzad.hamad@uor.edu.krd
}

\begin{tabular}{l}
\hline Article Info \\
\hline Volume 5 - Special Issue: $4^{\text {th }}$ \\
International Conference on the Health \\
and Medical Science : Medical \\
Researches Improve Life Quality \\
(ICHMS 2020) \\
DOI: \\
10.24017/science.2020.ICHMS2020.3 \\
Article history: \\
Received: 22 September 2020 \\
Accepted: 27 September 2020 \\
\hline
\end{tabular}

Keywords:

Sacrococcygeal Pilonidal

Sinus,

primary closure,

midline suture

\begin{abstract}
Sacrococcygeal Pilonidal sinus disease is common chronic inflammatory disease affecting chiefly young adult male. It cause much discomfort and morbidity and affect negatively the quality of life of patients. There are various techniques of surgical treatment for the chronic sinuses but still there is no gold standard one. The aim of this study to report our experience with excision and midline closure technique of chronic Sacrococcygeal Pilonidal sinus disease and to identify the outcome of the procedure for postoperative wound complications and recurrence rate. This is a retrospective study with telephone contact and review of 36 patients operated for Sacrococcygeal pilonidal sinus disease from January 2011 through January 2016 under care of one consultant surgeon (the Author) in Public and Private Hospitals in Rania, Sulaimani, Iraq. Inclusion criteria was all patients with chronic midline located sinuses without evidence of acute inflammation. Exclusion criteria was all infected off midline located sinuses and recurrent sinuses. Elliptical Excision of the sinuses with primary midline closure over a vacuum drainage performed. End point of this study was rate of wound complications and recurrence of sinus. Thirty six patients with median age 22 years (range 14-40) with 24/12 male /female ratio. Median follow up was 24 months (12 - 66 months), the recurrence occurred in $3 / 36$ ( $8.3 \%$ ) patients at a median of 12 months (range 5 - 48), failure of treatment in $5 / 36$ (13.9\%) patients, and postoperative wound complications was seen in $5 / 36$ (13.9\%) patients. In the conclusion, excision and
\end{abstract}


primary midline closure is simple, effective and preferable procedure for management of uncomplicated Sacrococcygeal pilonidal sinus disease associated with early wound healing and low rate of postoperative wound complications and recurrence rate.

Copyright (C) 2020 Kurdistan Journal of Applied Research.

All rights reserved.

\section{INTRODUCTION}

Sacrococcygeal Pilonidal sinus disease (SPND) is a chronic common surgical condition usually affecting mostly young adult, but not uncommon in children [1] . It is usually a blind tract, that extends from the skin of intergluteal cleft down to the fat over the sacrum [2] The incidence is recorded at 26 per 100,000 population [3-5]. Women affected less frequently than men in a ratio of 1:3 [6], but recent literature confirms the contribution of ladies suffering from SPND is substantial [7]. There are many risk factors for SPND which include hirsutism, sedentary life style, deep natal cleft, male gender, obesity, previous family history and poor personal hygiene [6, 8].There is controversy about its pathogenesis but much evidences are supporting its acquired origin rather than congenital [9]. Sacrococcygeal Pilonidal sinus disease had been seen also in some women with little hair and this could be interpreted the theory of congenital natal cleft dimple ,although different theories relating a congenital origin to pilonidal sinuses has been criticized and are believed lacking proof [10]. There are two different hypothesis related to the pathogenesis of SPND as acquired disease . Karydakis believes SPND is acquired disease and there are many factors playing role in the pathogenesis which include: Brocken hair invasion, force for hair insertion and the vulnerability of the skin to the insertion of hair at the depth of the natal cleft [7].

Another hypothesis by Bascom also supporting acquired origin of SPND is hyperkeratosis which lead to follicular obstruction and subsequently dilatation and rupture of the follicle then followed by secondary infection and formation of abscess and sinus, later on the hair come to lie in the preformed openings[11] .

Gross appearance of the chronic SPND seen as one or multiple openings in the natal cleft passing downward to the subcutaneous tissue and fat over the sacrum ,this will end in a cavity which contain hairs that not attached within the sinus and usually has tapered end like shedding hairs[6]. Sometimes there are secondary sinuses which arises from the original cavity and opens by an orifice on the skin off midline .Microscopically the lining of the deep cavity composed of granulation tissue while the nearer points of the sinus to the skin surface covered with squamous epithelium [10].

Clinical presentation of SPND may be acute as abscess or chronic sinus with intermittent discharging in which both conditions causing much discomfort and morbidity for patient and need intervention. In case of abscess ,its commonly located in the midline of natal cleft or protruding to one side of the cleft. Patients with chronic conditions have variable presentation ranging from simple cyst to single or multiple pits in the midline of natal cleft or laterally located [12]. There is no consensus about the classification of types of SPND yet and wellrecognized and pragmatic classification system to guide clinical practice is needed [13].

Diagnosis of SPND is easy clinically that is why investigations are rarely needed except in seldom conditions where imaging study, endosonography and magnetic resonance imaging, might be indicated to exclude associated anorectal fistula or underlying sacral osteomyelitis[6].

The treatment of abscess is straight forward by incision and drainage but to date there has been little agreement on what is the best method of treating chronic SPND . There are 
different surgical interventions for treating the chronic SPND ranging from limited versus wide excision ,secondary versus primary closure, different flap closure, and minimally invasive techniques which includes pit-picking, sinusectomy, phenol instillation, Laser ablation of the subcutaneous tract and lastly the most recent one is video-assisted endoscopic ablation procedures [11]. Although the treatment nearly always is surgical, and the goal of intervention is rapid healing with minimum morbidity and least recurrence ,but there is no consensus on the ideal surgical approach for management of the chronic SPND [6]. The reason is high incidence of morbidity and postoperative wound complication and recurrence in most of the surgical procedures. The option of a special surgical procedure is depending on how much the surgeon is skillful and acquainted with the surgical technique and the detected outcomes in term of a low recurrence rate of the sinus and of fast healing of the operative wound [14]. The commonest current choices for operative procedures are excision with primary midline closure or off midline closure or using different types of flaps or leaving the wound open to heal with secondary intention [15]. The aim of this study is to describe the short and long term outcome after excision and primary midline closure with drainage of chronic Sacrococcygeal Pilonidal sinus disease in terms of postoperative complications and recurrence rate.

\section{METHODS AND PATIENTS}

This is retrospective descriptive study run out in Public and Private Hospitals in Rania, Sulaimani, Iraq from January 2011 to January 2017. The population was 55 patients with Sacrococcygeal Pilonidal sinus disease operated on by single surgeon (the Author), but only 36 patients was accessed by telephone survey to assess recurrence of the condition due to changing their phone number .Inclusion criteria was non infected midline located natal cleft sinuses with minimal discharge. Exclusion criteria were all infected, off midline located and recurrent sinuses.

All Patients were assessed preoperatively by anesthetist for fitness for anesthesia few days before the operation, and all of them asked to shave the natal cleft and surrounding gluteal region the day before the operation. On the day of operation, informed consent has been taken with administering Ampliclox 1gram intravenously before induction of anesthesia. The patients put in Jackknife position with double adhesive plaster exploring the intergluteal region (Figure 1 A). The operative field draped and prepared with Povidone iodine, a symmetrical narrow elliptical excision of all sinuses done down to sacral fascia after probing all the sinus opening (Figure $1 \mathrm{~B} \& \mathrm{C}$ ). Gluteal fascia sutured by interrupted polyglycolic acid No. 1 (Vicryl ${ }^{\circledR}$ ) sutures with $1 \mathrm{~cm}$ apart, after good hemostasis by electrocoagulation, suction drain gauge 10 left at the base of the wound through separate stab incision (Figure $1 \mathrm{C}$ ). Skin approximated by polypropylene 2.0 (Prolen ${ }^{\circledR}$ ) interrupted mattress stiches (Figure 1 D). All patients left the hospital after 6 hours and removal of drain was after 48 hours. Postoperative oral ciprofloxacin 500mg with Metronidazole 500mg for 2 weeks continued with oral Mefanemic acid as on need analgesia. The first visit was performed 48 hours after operation for removing the drain and patient instructed to do every other day changing of dressing with using povidone Iodine disinfectant. On the second visit the stiches removed on $12^{\text {th }}$ postoperative day. 

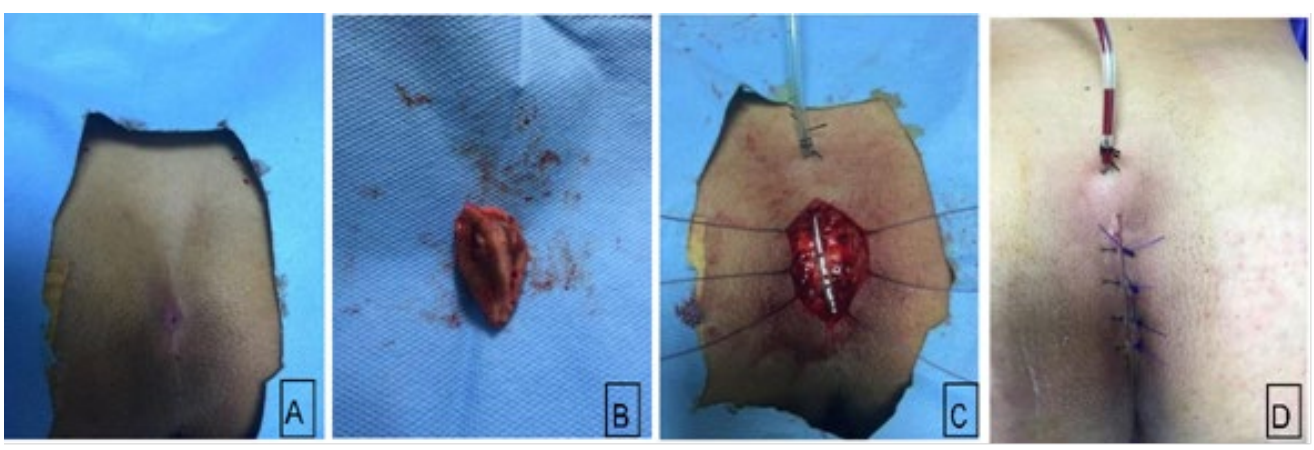

Figure 1: A. preoperative Sacrococcygeal Pilonidal sinus disease. B. Elliptical excised sinus. C. Subcutaneous sutures passed over tube redi vac drain. D. Skin closure at midline with redi vac drain in place.

The follow up of patients was by reviewing in the outpatient department and the private clinics after 1 month of removing the sutures. Instructions were given for all patients which include bathing every day in summer and not less than 2 times in winter, with shaving natal cleft once every 2 weeks and avoid long journey by car, heavy weight bearing, excessive physical strain and sport for few months postoperatively. All patients informed to come back whenever wound infection or recurrence happened. Wound infection defined as purulent discharge from the wound and recurrence was defined as reappearance of symptoms and sinus after a period of complete wound healing (Figure 2). Data was analyzed using SPSS version 20. Fisher's Exact test of statistical significance has been used. $P$ value less than 0.05 was regarded significant.

\section{RESULTS}

Medical records of only 36 patients whose operated from January 2011 to January 2016 reviewed with a telephone survey has been arranged in February 2017 asking them about the recurrence of sinus. The other 19 patients could not be accessed due to the changing their mobile number and absence of postal address. There were 24 male and 12 female with a median age 22 years (range $14-40$ ). During the second visit of postoperative period $86.1 \%$ $($ No. $=31)$ experienced no complications while $5.6 \%($ No. $=2)$ patients had wound infection and $2.8 \%($ No. $=1)$ patient suffered wound disruption after removing the stiches and further $5.6 \%(\mathrm{No} .=2)$ patients continue with persistent sinus without a complete wound healing.

There were $8.3 \%(\mathrm{No} .=3)$ patients with recurrence of sinus after median 12 months (range 548).

Table 1: Characteristics of the patients and the outcome of operation

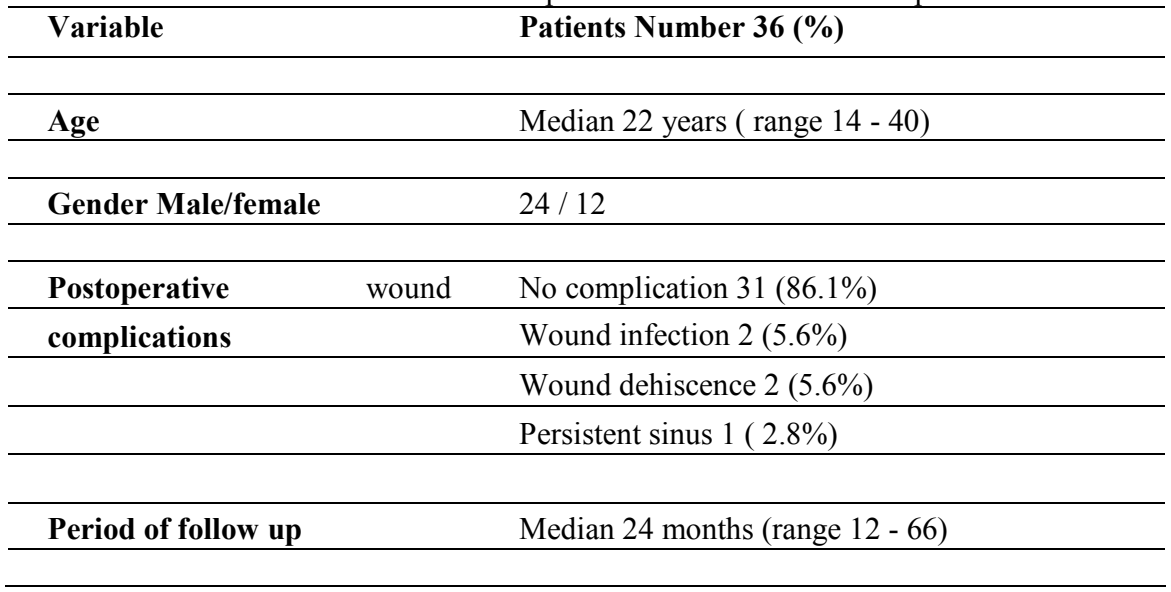

Kurdistan Journal of Applied Research $\mid 4^{\text {th }}$ International Conference on the Health and Medical Science: Medical Researches Improve Life Quality (ICHMS 2020) | 22 


\begin{tabular}{ll}
\hline Outcome of operation & No recurrence $28(77.8 \%)$ \\
\hline & Failure of treatment $5(13.9 \%)$ \\
\cline { 2 - 2 } & Recurrence $3(8.3 \%)$ \\
\hline
\end{tabular}

There was no a significant difference of postoperative wound complication and recurrence in relation to age and gender, as $\mathrm{p}$ value were greater than 0.05 .

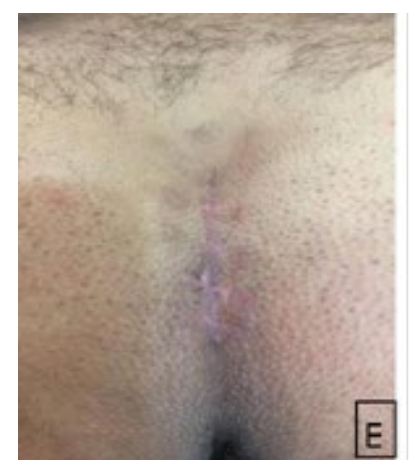

Figure 2: The completely healed wound at 3 months

\section{DISCUSSION}

This study set out with the aim of assessing the outcome of excision with primary midline closure as a procedure in treating chronic SPND in both aspects of wound complication and recurrence rate. There are various types of surgical interventions for chronic pilonidal sinus ranging from simple excision with closure to complex rotational flap or leaving the wound open to heal by secondary intention $[4,5]$. This indicate that there is no agreement on determining the ideal surgical technique [16] and there is no a gold standard surgical procedure for the treatment of chronic pilonidal sinus [17]. The main requisites of a perfect treatment are high rate of healing, low rate of postoperative complications ,low incidence of recurrence and performing the operation as a day case surgery as well as avoiding of general and spinal anesthesia and minimal discomfort and pain with early return to work [18]. In this study only two parameters had been taken in the consideration, which are the rate of wound complication and the rate of recurrence. Furthermore, postoperative wound complications and recurrence rates are the important parameters in measuring the effectiveness of the surgical procedure that is performed for pilonidal sinus [19]. The current study has found that the incidence of postoperative wound infection was $5.6 \%(\mathrm{No} .=2)$ which is much less than the other studies done by Gilani et al., Marco et al. , Kareem and Popeskou et al. in which the incidence of wound infection were $9.7 \%, 13 \%, 30 \%$ and $31 \%$ respectively $[14,15,17,20]$. The high infection rate in these studies may be related to the inadequate prescription of antibiotics as only a prophylactic single dose had been given by Popeskou et al. and SPND operation is regarded as contaminated surgery and it needs at least 5 days of postoperative antibiotics. In relation to our study, although all patients had already taken prophylactic antibiotics but a possible explanation of this result is noncompliance of patients to surgeon's instruction and the lack of adequate personal hygiene. This result is much lower than that the reported by Dudink et al. in which they found the postoperative wound infection after midline closure operation which is reaching to $73.7 \%$ [3]. Another important finding was that in which $2.8 \%$ (one patient) continues with persistent sinus after removing of the stiches, and a possible explanation for this finding might be that, during the excision and after the removing of one of the laterally extended sinuses, it leads to form a dead space with subsequent pocket of seroma and persistence of sinus, although there was a drain but it is leaving it for 48 hours and does not prevent the collection of serum and keeping it more than this time was heralding the 
infection. The effect of leaving closed suction drain after SPND surgery is controversial and the explicit decision cannot be withdrawn from the current literature review [14], but in our view even extremely thorough hemostasis does not prevent the aggregation of some blood and serum which will be a good media for the pathogenic microorganisms and causing wound infection, that is why leaving the closed suction drain is necessary and useful. Moreover, the results of this study show that $5.6 \%($ No. $=2)$ of the patients present with disruption of wound after removing the sutures which is much less than what has been done by other researches; for instance, Dudink et al. in which $79 \%$ of intervention result in wound dehiscence [3]. A possible explanation for the wound dehiscence in current study for one of the patients might be due to the closeness of the sinuses and the operative field and incision to anal verge and maceration of skin due to sweating and wetness which might be the cause of contamination and non-healing of the wound, and the possible explanation for the second patient is that excessive using of coagulation for hemostasis causing much dead tissue as well as pulling force from the subcutaneous fascia might be the cause of wound dehiscence. Gluteal traction forces on the wound and macerated skin in a deep raphe prevent appropriate wound healing [3].

The results of this study did not show any significant change in the recurrence rate in comparison with previous studies .In current study recurrence was observed in 3 patients $8.3 \%$ after median 24 months (range 12-66) follow up, which is nearly comparable with other studies done by Gilani et al., Marco et al. and Kareem in which the recurrence after primary midline closure with drain were $9 \%, 9.4 \%$ and $10 \%$ respectively $[14,15,17]$. The recurrence rates following cutting out the sinuses and primary closure in a study done by Iesalnieks et al. was $42 \%$ [21]. Primary closure of the wound unavoidably cause substantial tensity and this has been in charge of the high rate of recurrent disease and wound disruption after primary suturing [22]. The high rate of recurrence is lower in tension free primary closure as well as other wound complications [23]. Another factor might have role in the recurrence is noncompliance of patients with good hygiene and removal of hair as there is evidence that there is big difference in incidence of recurrence between those have regular style of removing hair of natal cleft from those who neglect personal hygienic measures [24], although randomized controlled trials is required to have evidence based decision about choosing the optimal way and methods of removing hair.

There was no substantial difference between age and gender neither with the rate of postoperative wound complications nor with recurrence as $\mathrm{p}$ value is greater than 0.05 , this result was in the agreement with another study done by Akin et al. [25], but in another study done by Almajid et al. young age was the most predominant factor associated with recurrence of pilonidal sinus [26].

The aim of the ongoing study was to determine the rate of wound complications and recurrence after elliptical excision and primary midline closure with suction drainage of SPND. This study has disclosed a low rate of postoperative wound complications and recurrence after this procedure. These data suggest that a good outcome can be achieved through applying excision and primary midline closure procedure selectively in non-infected, midline located sinuses with proper attention to using prophylactic disinfection measures which is including using of antibiotics and avoiding leaving dead space and excessive using of coagulation. Although, the current study based on a small sample size of the participants, the finding will serve as a base for the future further wider prospective studies about the current method of managing chronic SPND.

\section{CONCLUSION}

We conclude that long term results propose that primary cutting out of sinuses with midline closure with suction drain for uncomplicated Sacrococcygeal Pilonidal sinus disease is an effective and simple procedure. A limitation of this study is that we could not access all the patients whom had been operated during that period and nearly one third of them missed from

Kurdistan Journal of Applied Research $\mid 4^{\text {th }}$ International Conference on the Health and Medical Science: Medical Researches Improve Life Quality (ICHMS 2020) | 24 
follow up. It is recommended that further research to be undertaken on larger samples, as randomized controlled trial to compare different surgical procedures of treatment for chronic Sacrococcygeal Pilonidal sinus disease.

\section{REFERENCE}

[1] S. Braungart, M. Powis, J. R. Sutcliffe, and I. D. Sugarman, "Improving outcomes in pilonidal sinus disease," Journal of pediatric surgery, 2015.

[2] T. A. Dass, M. Zaz, A. Rather, and S. Bari, "Elliptical excision with midline primary closure versus rhomboid excision with limberg flap reconstruction in sacrococcygeal pilonidal disease: a prospective, randomized study," Indian J Surg, vol. 74, no. 4, pp. 305-8, Aug 2012.

[3] J. V. R. Dudink, S. Nienhuijs, J. Heemskerk, "Secondary healing verSuS midline cloSure and modified BaScom natal cleft lift for pilonidal SinuS diSeaSe," Scandinavian Journal of Surgery, no. 2, pp. 110-113, 2011.

[4] R. L. Harries, A. Alqallaf, J. Torkington, and K. G. Harding, "Management of sacrococcygeal pilonidal sinus disease," International Wound Journal, vol. 16, no. 2, pp. 370-378, 2018.

[5] A. Isik, O. Idiz, and D. Firat, "Novel Approaches in Pilonidal Sinus Treatment," Prague Medical Report, vol. 117 , no. 4 , pp. 145-152, 2016.

[6] V. de Parades, D. Bouchard, M. Janier, and A. Berger, "Pilonidal sinus disease," J Visc Surg, vol. 150, no. 4, pp. 237-47, Sep 2013.

[7] M. M. Luedi, P. Schober, V. K. Stauffer, M. Diekmann, and D. Doll, "Global Gender Differences in Pilonidal Sinus Disease: A Random-Effects Meta-Analysis," World Journal of Surgery, 2020.

[8] M. Milone, N. Velotti, M. Manigrasso, P. Anoldo, F. Milone, and G. D. De Palma, "Long-term follow-up for pilonidal sinus surgery: A review of literature with metanalysis," The Surgeon, vol. 16, no. 5, pp. 315320, 2018.

[9] S. Arslan, E. Karadeniz, G. Ozturk, B. Aydinli, M. C. Bayraktutan, and S. S. Atamanalp, "Modified Primary Closure Method for the Treatment of Pilonidal Sinus," Eurasian J Med, vol. 48, no. 2, pp. 84-9, Jun 2016.

[10] R. BREARLEY, "Pilonidal Sinus A New Theory Of Origin," The British Journal Of Surgery, pp. 62-68, 1955.

[11] I. Iesalnieks and A. Ommer, "The management of pilonidal sinus," Deutsches Aerzteblatt Online, 2019.

[12] $\quad$ L. J. a. S. J*, "Pilonidal Sinus Disease - A Literature Review," World Journal of Surgery and Surgical Research, vol. 2, 2019.

[13] E. M. Beal, M. J. Lee, D. Hind, A. P. Wysocki, F. Yang, and S. R. Brown, "A systematic review of classification systems for pilonidal sinus," Techniques in Coloproctology, vol. 23, no. 5, pp. 435-443, 2019.

[14] M. Marco, M. Mario, S. Giuseppe, L. Maddalena, and M. Francesco, "Effectiveness of a drain in surgical treatment of sacrococcygeal pilonidal disease. Results of a randomized and controlled clinical trial on 803 consecutive patients," International Journal of Colorectal Disease, vol. 26, no. 12, pp. 1601-1607, 2011.

[15] S. N. Gilani, H. Furlong, K. Reichardt, A. O. Nasr, G. Theophilou, and T. N. Walsh, "Excision and primary closure of pilonidal sinus disease: worthwhile option with an acceptable recurrence rate," Ir J Med Sci, vol. 180, no. 1, pp. 173-6, Mar 2011.

[16] S. M. Al-salamah, M. I. Hussain, and S. M. Mirza, "Original Article Excision with or without primary closure for Pilonidal sinus disease," J Pak Med Assoc, vol. 57, no. 8, pp. 388-391, 2007.

[17] T. S. Kareem, "Surgical treatment of chronic sacrococcygeal pilonidal sinus," saudi medical Journal, vol. 964, no. March, pp. 1534-1537, 2006.

[18] M. Milone et al., "Intradermal absorbable sutures to close pilonidal sinus wounds: a safe closure method?," Surg Today, vol. 44, no. 9, pp. 1638-42, Sep 2014.

[19] A. S. Karaca, R. Ali, M. Capar, and S. Karaca, "Comparison of Limberg flap and excision and primary closure of pilonidal sinus disease, in terms of quality of life and complications," J Korean Surg Soc, vol. 85 , no. 5, pp. 236-9, Nov 2013.

[20] S. Popeskou, D. Christoforidis, C. Ruffieux, and N. Demartines, "Wound infection after excision and primary midline closure for pilonidal disease: risk factor analysis to improve patient selection," World $J$ Surg, vol. 35, no. 1, pp. 206-11, Jan 2011.

[21] I. Iesalnieks, A. Fürst, M. Rentsch, and K. Jauch, "Primary midline closure after excision of a pilonidal sinus is associated with a high recurrence rate," Der Chirurg; Zeitschrift fur alle Gebiete der operativen Medizen, vol. 74, no. 5, pp. 461-468, 2003.

[22] J. Horwood, D. Hanratty, P. Chandran, and P. Billings, "Primary closure or rhomboid excision and Limberg flap for the management of primary sacrococcygeal pilonidal disease? A meta-analysis of randomized controlled trials," Colorectal disease : the official journal of the Association of Coloproctology of Great Britain and Ireland, vol. 14, no. 2, pp. 143-51, 2012.

[23] A. Okuş, B. Sevinç, O. Karahan, and M. a. Eryilmaz, "Comparison of Limberg flap and tension-free primary closure during pilonidal sinus surgery," World journal of surgery, vol. 36, no. 2, pp. 431-5, 2012.

[24] A. A. Pronk, L. Eppink, N. Smakman, and E. J. B. Furnee, "The effect of hair removal after surgery for sacrococcygeal pilonidal sinus disease: a systematic review of the literature," Techniques in Coloproctology, vol. 22, no. 1, pp. 7-14, 2017.

Kurdistan Journal of Applied Research $\mid 4^{\text {th }}$ International Conference on the Health and Medical Science: Medical Researches Improve Life Quality (ICHMS 2020) | 25 
[25] S. G. Akin Onder1, Murat Kapan1, Mehmet Toker2, Zulfu Arikanoglu1, Yilmaz Palanci3, Bilsel Bac, "Pilonidal Sinus Disease: Risk Factors for Postoperative Complications and Recurrence," international surgery, vol. 97, pp. 224-229, 2012

[26] F. Almajid, A. Alabdrabalnabi, and K. Almulhim, "The risk of recurrence of Pilonidal disease after surgical management," Saudi Medical Journal, vol. 38, no. 1, pp. 70-74, 2017.

Kurdistan Journal of Applied Research $\mid 4^{\text {th }}$ International Conference on the Health and Medical Science: Medical Researches Improve Life Quality (ICHMS 2020) | 26 